\title{
Damage Characteristics of Sandstone Subjected to Coupled Effect of Freezing-Thawing Cycles and Acid Environment
}

\author{
Hongwei Deng $\left(\mathbb{D}\right.$, Songtao Yu $\mathbb{D}^{D}$, and Junren Deng \\ School of Resources and Safety Engineering, Central South University, Changsha 410083, China \\ Correspondence should be addressed to Songtao Yu; yusongtao92@163.com
}

Received 21 March 2018; Accepted 31 May 2018; Published 5 July 2018

Academic Editor: Claudio Tamagnini

Copyright (c) 2018 Hongwei Deng et al. This is an open access article distributed under the Creative Commons Attribution License, which permits unrestricted use, distribution, and reproduction in any medium, provided the original work is properly cited.

\begin{abstract}
In order to figure out the damage characteristics and mechanisms of sandstone under coupled effect of acid erosion and recurrent freezing-thawing cycles, sulfuric acid is chosen as acid solution, and sandstone, representative stone in Sichuan province, is chosen as a sample to conduct the freezing-thawing cycling test. In the meantime, chemical component of the solution is also tested and recorded in the progress of freezing-thawing cycling. Then, the nuclear magnetic resonance (NMR) test and magnetic resonance images (MRI) test on samples are conducted with the help of the AniMR-150 NMR imaging system. After a series of tests, the sample's appearance, dry mass, porosity, T2 spectrum, solution's $\mathrm{pH}$, solution's metallic ion concentration, and magnetic resonance images are obtained and analyzed. The results show that dry mass loss and porosity grow with F-T cycles increase and $\mathrm{pH}$ value decrease. Montmorillonite, illite, and clay in sandstone react with sulfuric acid solution; as a consequence, $\mathrm{K}^{+}, \mathrm{Mg}^{2+}, \mathrm{Fe}^{3+}$, and $\mathrm{Al}^{3+}$ separate out, and the solution's $\mathrm{pH}$ and concentration of $\mathrm{K}^{+}, \mathrm{Mg}^{2+}, \mathrm{Fe}^{3+}$, and $\mathrm{Al}^{3+}$ increase with F-T cycles. Acid erosion and $\mathrm{F}-\mathrm{T}$ cycling lead to the generation of new micropores and expansion of micropores at the beginning; when the acid solution is exhausted, new micropores generate under the effect of freezing-thawing cycling, and micropores in samples keep developing and expanding with the increase of freezing-thawing cycles. Coupled effect of acid corrosion and recurrent freezing-thawing cycling causes much more serious deterioration to sandstone samples than acid corrosion.
\end{abstract}

\section{Introduction}

Freezing-thawing (F-T) cycles occur in many environments. As a kind of geological weathering, it is widely believed that the F-T cycle is the result of phase change between water and ice contained in materials that are induced by temperature change [1-3]. Usually, F-T cycles cause negative effects in real world. For example, F-T cycles are responsible for the degradation of material of cultural/historical buildings and monuments [4], the debasement of stability of road and $\mathrm{road} / \mathrm{railway}$ tunnel [5], and the occurrence of rock fall [6]. Gradually, F-T cycles are viewed as a source of natural hazard.

Additionally, the occurrence of F-T cycles is tightly coupled with chemistry environment, especially acidic water environment mainly caused by acid rain. Take southwestern China as an example, some parts of Sichuan province and Chongqing city, representative area of southwestern China which goes through seasonal F-T cycles, underwent acidic rain with an extreme low $\mathrm{pH}$ value reaching 3.05 (year 2004) and 2.79 (year 2012), respectively. Therefore, research on damage characteristics of rocks subjected to F-T cycles in acidic water environment is of great importance in engineering and environmental protection area, and it has gradually become a hot issue of research.

Research on F-T cycles of rocks began in early 20th century, and rich achievement has been gained. In terms of damage mechanism of rock subjected to F-T cycles, two explanations are widely known. One explanation is that ice crystallization pressure [7-10] is responsible for the induced flaws and damage in rock material. As pore water is constrained in pore network in rock material, once the temperature drops below the freezing point, water crystals into ice, as a consequence, $9 \%$ of volume growth occurs, and this exerts stress on surface of pore network. Once crystallization pressure exceeds the tensile strength of rock, flaws and 
damage will occur. Another explanation is that rock damage caused by F-T cycles derives from the migration of unfrozen water in rock material [11]. It is widely known that, in porous material like rock and concrete, water in large pore freeze easily, while water in small pore is difficult to freeze, as long as the pore size is small enough, pore water will remain unfrozen. It is the migration effect of unfrozen water driven by capillary pressure [7] and osmotic pressure [12] that deteriorated rock material. Walbert et al. [11] and Vlahou and Worster [13] pointed out that the mechanism of crystallization pressure is applicable to materials with low permeability, and the mechanism of migration is applicable to materials with high permeability.

Mechanical and physical properties are connected with engineering tightly and directly, therefore, most efforts have been made to study the damage mechanism of rocks subjected to recurrent F-T cycles. Wiman [14] conducted frost shattering experiments for slate, schist, granite, quartzite, and gneiss and monitored the sample's weight and porosity. Hori and Morihiro [15] studied water freezing and movement in pores by using a micromechanical model and then predicted the deterioration degree of rock based on these microscopic processes. To study the deterioration of andesite in recurrent F-T cycles, Yavuz [16] recorded and contrasted porosity, density, water absorption, P-wave velocity, Schmidt hardness, abrasion, and uniaxial compressive strength of rock specimens after every ten cycles. Taking limestone as rock samples, Bayram [17] measured uniaxial strength, tensile strength, flexural strength, impact strength, modulus of elasticity, porosity, and water absorption as variability to study the deteriorations of stones. To evaluate the role of critical degree of saturation in F-T damage, limestone samples with eight different degrees of saturations were adopted by Al-Omari et al. [18], and porosity, tensile strength, ultrasonic pulse velocity, mercury intrusion porosimetry, and scanning electron microscopy techniques were employed to analyze the conditions of samples during the cycles. Results indicated that a saturation of $80-85 \%$ is the critical saturation of limestone in this test. Akin and Özsan [19] used integrity as indicator to investigate the longterm performance/durability of yellow travertine against recurrent F-T cycles. Based on integrity of rock, a decay function (Mutluturk et al. [20], Ghobadi and Babazadeh [21]) was proposed and used to predict the long-term durability of rock against F-T cycles. Zhou et al. [22] studied sandstone's microscopic damage and dynamic mechanical properties subjected to recurrent F-T cycles based on NMR tests and impact loading tests.

In recent years, study on erosion of rocks in different chemistry environments has also become a forefront of research in geotechnical engineering. To figure out the effects of chemical solution on the shear behavior of sandstone, Feucht and Logan [23] carried out a test which dealt sandstone samples with three chemistry solutions $(\mathrm{NaCl}$, $\mathrm{CaCl}_{2}$, and $\mathrm{Na}_{2} \mathrm{SO}_{4}$ ) and monitored samples' friction coefficient and strength. Feng et al. [24] immersed sandstone samples of triaxial compression into $\mathrm{NaCl}, \mathrm{CaCl}_{2}$, and $\mathrm{NaHCO}_{3}$ solutions and the Yellow river water to investigate the mechanisms of damage evolution of sandstone and proposed a damage model based on the chemical corrosive influence and CT values. Deng et al. [25] conducted recurrent F-T cycle experiments under the condition of $\mathrm{H}_{2} \mathrm{SO}_{4}$, $\mathrm{NaOH}$, and $\mathrm{NaCl}$ solutions and pure water to investigate the coupled effect of F-T cycles and chemical solution on sandstone, and the result showed that $\mathrm{NaOH}$ causes stronger damage to rock samples used in these experiments than other solutions. By subjecting granite, parent rocks for nuclear waste storage, to strong acid solutions and strong alkaline solutions, Han et al. [26] explored the deterioration and mechanical properties of granite under various chemistry environments and found that strong acid solutions may aggravate chemical damage deterioration in granite while strong alkaline solutions have braking effect on chemical damage deterioration in granite. Miao et al. [27] used distilled water and $\mathrm{NaCl}$ solutions as chemistry solution to investigate granite's damage effects, aging features, and mechanisms after subjecting to solutions with different $\mathrm{pH}$ and flow rates.

In the progress of exploring internal structure and damage of rock material, a series of damage detection technologies and facilities emerged, among which nuclear magnetic resonance (NMR), scanning electron microscope (SEM), and computerized tomography (CT) are three extensively used damage detection facilities. In a experiment to investigate long-term performance of yellow travertine against various environmental factors, Akin and Özsan [19] employed a scanning electron microscope (SEM) to check the mineralogical texture of samples. Miao et al. [27] observed the effects of acidic chemical corrosion on microscopic structures of granite by SEM. Feng et al. [24] monitored experiments on sandstone damage evolution during triaxial compression with chemical corrosion with real-time computerized tomography (CT). Tim et al. [10] studied the pore scale dynamics related to F-T by micro-CT. With the help of NMR, Zhou et al. [22] obtained parameters (porosity, T2 distribution, and NMR images) of sandstone subjected to recurrent F-T cycles, which revealed sandstone samples' development of damage. Li et al. [28] researched the deterioration characteristics of the microscopic structure of sandstones in freezing-thawing cycles by means of the NMR test and found that the spatial distribution of sandstone pores after freezing-thawing cycles has fractal features within certain range. Among these damage detection technologies, SEM could picture internal microstructure of rock, while the perspective of it is limited strictly which means it can only give a small and partial view to the surface of rock. CT can offer a whole and $3 \mathrm{D}$ view of rock samples, but it could only be used in real-time observation and CT scanning could not reflect the features of microscopic structure. NMR [28] is a nondestructive detection equipment, and it could detect the rock sample's porosity and pore size distribution and show internal pore structure by magnetic resonance imaging (MRI). NMR is an effective mean to investigate the microstructure of rock.

Currently, published research studies on the damage mechanisms of rock under chemical erosion and recurrent F-T cycles are deficient. However, geotechnical engineering subjected to the couple effect of these two factors do exist. 
TABLE 1: Quality percentage of sandstone's mineral component.

\begin{tabular}{lcccc}
\hline Component & Quartz & Illite & Montmorillonite & $\begin{array}{c}\text { Clay (mainly } \\
\left.\mathrm{Fe}_{2} \mathrm{O}_{3}\right)\end{array}$ \\
\hline Quality (\%) & 95.1 & 1.48 & 2.32 & 1.1 \\
\hline
\end{tabular}

TABLE 2: Original physical parameter of sandstone.

\begin{tabular}{ccc}
\hline $\begin{array}{c}\text { Dry density } \\
\rho\left(\mathrm{g} / \mathrm{cm}^{3}\right)\end{array}$ & $\begin{array}{c}\text { Natural moisture } \\
\text { content }(\%)\end{array}$ & $\begin{array}{c}\text { Initial } \\
\text { porosity }(\%)\end{array}$ \\
\hline 2.10 & 3.08 & 10.10 \\
\hline
\end{tabular}

Therefore, sandstone from Sichuan province in China which suffered from seasonal F-T cycles and extreme acid rainfall was chosen as the rock sample for the joint disposal of recurrent F-T cycles and acidic solution soaking, and NMR, MRI, and other technologies were adopted as detection technology. Then, the changes of the dry mass, porosity, T2 distribution, MRI results, and chemical component of sandstone after different F-T cycles were obtained and analyzed to explore how this coupled effect deteriorates the sandstone in this paper.

\section{Materials and Methods}

2.1. Rock Samples and Acid Solution. Sandstone used in this experiment was taken from the north of Sichuan province which underwent couple effects of seasonal F-T cycles and acid rainfall. The sandstone is medium fine; it mainly consists of quartz and clay minerals, and mineral composition of sandstone samples are listed in Table 1. All rock samples were taken from an intact and unweathered sandstone, and there was no visible joints on it. The samples were obtained by the water drilling method, and they were made into standard cylinder with a diameter of $(50 \pm 1) \mathrm{mm}$ and height of $(100 \pm 1) \mathrm{mm}$. These samples were selected in accordance with natural porosity (about 10\%), and 60 samples were picked in this experiment. Rock samples were set into $\mathrm{O}(0$ cycles), A (10 cycles), B ( 20 cycles), C (30 cycles), D (40 cycles), and E (50 cycles) groups (six groups); each group included four series, 1 $(\mathrm{pH}=2.8), 2(\mathrm{pH}=4.2), 3(\mathrm{pH}=5.6)$, and $4(\mathrm{pH}=7.0)$, and there were three samples for each series. The mineral component and original property of sandstone are listed in Tables 1 and 2, respectively.

Acid solution in this experiment was made from sulfuric acid and distilled water to simulate the chemical erosion of acid rainfall on sandstone. The $\mathrm{pH}$ of the acid solution was set into 4 levels $(\mathrm{pH}=2.8, \mathrm{pH}=4.2, \mathrm{pH}=5.6$, and $\mathrm{pH}=7.0$ (distilled water)), respectively, to monitor the effect of acidity on sandstone damage.

2.2. Experimental Facilities. Facilities employed in this experiment include the TDS-300 concrete freeze-thaw test machine, AniMR-150 NMR imaging system, vacuum saturation machine, PL4002 electronic balance with precision of $\pm 0.01 \mathrm{~g}$, drying box with precision of $\pm 0.1^{\circ} \mathrm{C}$, and pHS-3C $\mathrm{pH}$ meter with precision of $\pm 0.01 \mathrm{pH}$. TDS-300 concrete freeze-thaw test machine is manufactured by Donghua

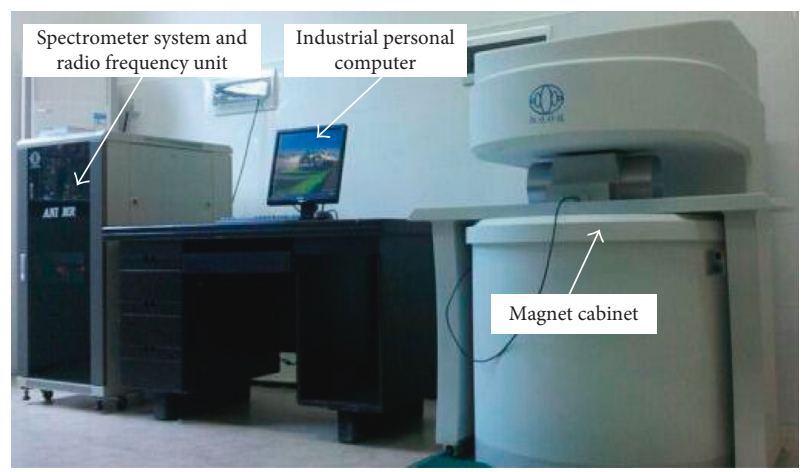

Figure 1: AniMR-150 NMR imaging system.

Testing Equipment Company, Ltd., Suzhou; it can apply a temperature range of $-40^{\circ} \mathrm{C}$ to $+40^{\circ} \mathrm{C}$ to rock samples, and it is an automated machine [25]. The vacuum saturation machine and AniMR-150 NMR imaging system are manufactured by Niumag Electric Technology Company, Ltd., Shanghai. The AniMR-150 NMR imaging system contains two main test systems, namely, nuclear magnetic resonance (NMR) and magnetic resonance images (MRI) test systems, and they were often used in other research studies $[22,25,28,29]$. Its picture is shown in Figure 1.

\subsection{Experimental Methods}

2.3.1. Freezing-Thawing Cycling Test. Before the recurrent F-T cycling started, all samples were vacuum saturated for 4 hours with vacuum pressure of $0.1 \mathrm{MPa}$ and soaked into distilled water for 24 hours [28]. Samples of series 1, 2, 3, and 4 were immersed into solutions with $\mathrm{pH}$ of $2.8,4.2,5.6$, and 7.0, respectively. And then, solutions immersed with series of sandstone samples were placed into the TDS-300 concrete freeze-thaw test machine for recurrent F-T cycles. In this test, samples were frozen at $-20^{\circ} \mathrm{C}$ for 4 hours and thawed at $+20^{\circ} \mathrm{C}$ for 4 hours. All samples were taken out of the TDS300 concrete freeze-thaw test machine and acid solution to observe their change in physical appearance after each 10 F-T cycles, and at the same time, dry mass of samples were also measured.

2.3.2. NMR and MRI Test. NMR and MRI technology conduct nondestructive test of inner structure of rock material based on detecting $\mathrm{H}$-proton of fluid water [29]. Therefore, samples must be saturated in the process of test. As samples were vacuum saturated for 4 hours with vacuum pressure of $0.1 \mathrm{MPa}$ and soaked into corresponding solutions, rock samples were taken out of solutions and wiped with wet towel to clear congealed water on the surface before conducting NMR and MRI tests. Then, they were wrapped with preservative films instantly to prevent water evaporation in the process of NMR and MRI tests. After that, rock samples were put into carrying bed of the AniMR-150 NMR imaging system $[25,28]$ to conduct NMR and MRI tests. The NMR and MRI tests were conducted after each $10 \mathrm{~F}-\mathrm{T}$ cycles. The changes of porosity, T2 distribution, and MRI of rock 


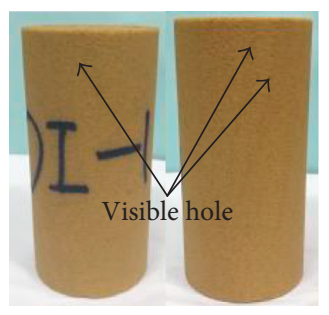

(a)

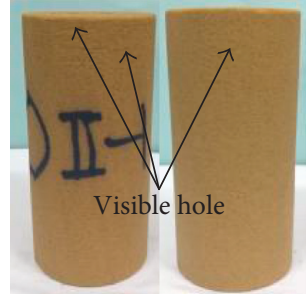

(b)

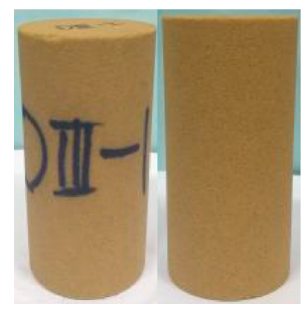

(c)

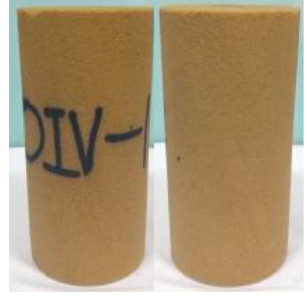

(d)

Figure 2: Figures of rock samples immersed in solution with different $\mathrm{pH}$ for a time-span of $40 \mathrm{~F}-\mathrm{T}$ cycles but did not undergo any F-T cycles. (a) $\mathrm{pH} 2.8$, (b) $\mathrm{pH} 4.2$, (c) $\mathrm{pH} 5.6$, and (d) $\mathrm{pH} 7.0$.

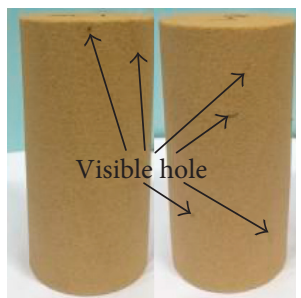

(a)

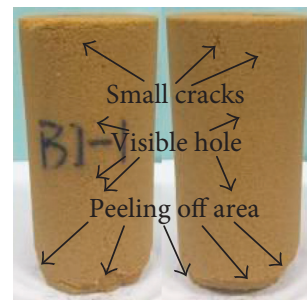

(b)

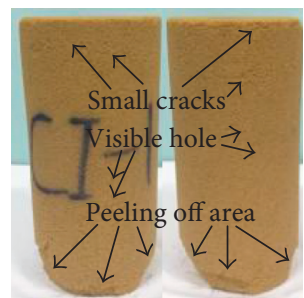

(c)

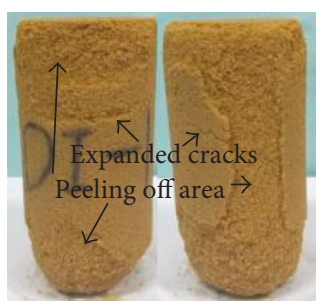

(d)

FiguRE 3: Figures of rock samples immersed in solution with pH of 2.8 and underwent different F-T cycles. (a) 10 cycles, (b) 20 cycles, (c) 30 cycles, and (d) 40 cycles.

samples were obtained. It should be noted that porosity in this NMR test is the ratio of the sample's moisture content and the sample's volume. To avoid the porosity error caused by deformation spallation of rock samples, the volumetric method was used to measure the sample's volume after the F-T cycling test.

2.3.3. Chemical Component Test. The chemical component test indicates the component test of acid solution and the rock sample. The acid solution component test in this experiment included the $\mathrm{pH}$ test and metallic ion concentration test of acid solution which mainly contained $\mathrm{H}^{+}, \mathrm{Na}^{+}$, $\mathrm{Mg}^{2+}, \mathrm{Al}^{3+}$, and $\mathrm{Fe}^{3+}$. The rock sample component test which focused on chemical element measurement was implemented through X-ray diffraction (XRD) analysis and X-ray fluorescence (XRF) analysis by experimental center of Changsha Research Institute of Mining and Metallurgy (China). In this experiment, the $\mathrm{pH}$ test and metallic ion concentration test of acid solution were conducted before and after each 10 F-T cycles, while the rock sample component test was conducted before the rock sample was treated with acid solution and after the rock sample went through $40 \mathrm{~F}-\mathrm{T}$ cycles in acid solution.

\section{Results and Discussion}

3.1. Samples' Appearance. Acid erosion and coupled effect of acid erosion and recurrent F-T cycling had caused different degrees of macroscopic deterioration to sandstone samples. Figure 2 includes pictures of sandstone samples that are immersed in solutions with $\mathrm{pH}$ of $2.8,4.2,5.6$, and 7.0 for a time-span of 40 F-T cycles, but it should be noted that they did not undergo any F-T cycles. Figure 2 shows acid corrosion effect on sandstone. By analyzing Figures 2(c) and 2(d), it is not hard to find that sandstone samples had no evident response to acid solution with $\mathrm{pH}$ of 5.6 and pure water $(\mathrm{pH}=7.0)$ even though they were soaked in corresponding solution for a time-span of $40 \mathrm{~F}-\mathrm{T}$ cycles. However, when the $\mathrm{pH}$ of acid solution descended, that is, when acidity increased, macroscopic deterioration appeared. Figures 2(a) and 2(b) exhibit appearance of sandstone immersed in acid solution with $\mathrm{pH}$ of 2.8 and 4.2 , respectively. These two pictures show that few discrete visible holes induced by acid corrosion appeared. By contrasting 4 pictures in Figure 2, it reveals that deterioration of sandstone enhanced with decline of the solution's $\mathrm{pH}$.

Figure 3 gives pictures of sandstone samples that are immersed in solutions with $\mathrm{pH}$ of 2.8 for $10,20,30$, and 40 F-T cycles, respectively. Comparing Figure 2(a) with Figure 3(a), it is easy to find that recurrent F-T cycling began causing damage even though rock samples underwent 10 F-T cycles only. As shown in Figure 3, after undergoing 10 F-T cycles, more visible holes appeared in the surface of samples than those samples immersed in acid solution only. When number of F-T cycles increased, damage of rock samples accumulated. After 20 F-T cycles (Figure 3(b)), more visible holes occurred; some small performative cracks generated as a result, and even a bit of sandstone layer around the end of samples peeled off because these areas have one more free surface and less constraint. After $30 \mathrm{~F}-\mathrm{T}$ cycles (Figure 3(c)), visible holes increased, through cracks increased and extended, and peeling off area expanded than those samples that suffered $20 \mathrm{~F}$-T cycles, but the peeling off area was still limited to the end of samples. Big change 
TABLE 3: Average dry mass of sandstone before and after suffering different $\mathrm{pH}$ and $\mathrm{F}-\mathrm{T}$ cycles.

\begin{tabular}{lccccc}
\hline \multirow{2}{*}{$\mathrm{pH}$} & Situation & \multicolumn{4}{c}{ Average mass of dry samples (g) } \\
& description & 10 & 20 & 30 & 40 \\
& cycles & cycles & cycles & cycles \\
\hline \multirow{3}{*}{2.8} & Before F-T & 385.10 & 394.46 & 392.20 & 394.00 \\
& After F-T & 381.44 & 387.4 & 380.29 & 355.04 \\
& Discrepancy & -3.66 & -7.06 & -11.92 & -38.96 \\
\hline \multirow{4}{*}{4.2} & Before F-T & 387.20 & 391.89 & 394.31 & 390.62 \\
& After F-T & 384.87 & 385.62 & 383.23 & 375.59 \\
& Discrepancy & -2.34 & -6.28 & -11.08 & -25.04 \\
\hline \multirow{4}{*}{5.6} & Before F-T & 386.52 & 388.07 & 395.07 & 391.77 \\
& After F-T & 384.32 & 383.35 & 380.37 & 370.82 \\
& Discrepancy & -2.2 & -4.73 & -9.06 & -20.9 \\
\hline \multirow{4}{*}{7.0} & Before F-T & 386.7 & 390.66 & 387.19 & 392.90 \\
& After F-T & 385.12 & 387.6 & 381.28 & 373.2 \\
& Discrepancy & -1.58 & -3.06 & -5.9 & -19.7 \\
\hline \multirow{4}{*}{} & & & & &
\end{tabular}

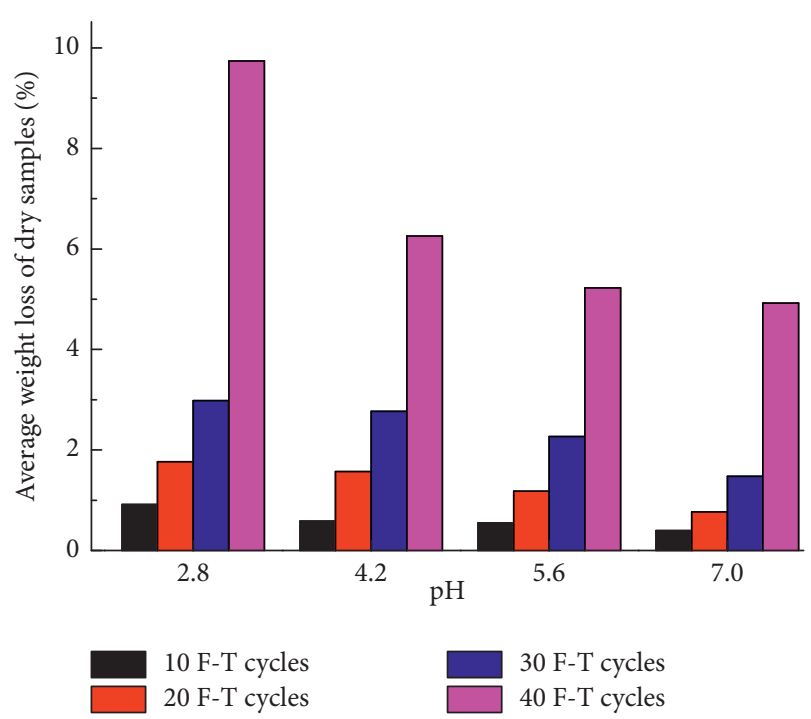

Figure 4: Changes of average dry mass loss of samples versus solutions' $\mathrm{pH}$ and F-T cycles.

appeared after samples underwent $40 \mathrm{~F}-\mathrm{T}$ cycles, and it is clearly shown in Figure 3(d) that the sample's damage accumulated to certain extent and peeling off was extended to whole samples. By comparing Figure 2 with Figure 3, it can be deduced that coupled effect of acid corrosion and recurrent F-T cycling had caused much more serious deterioration to sandstone samples than acid corrosion.

3.2. Dry Mass. Under the coupled effect of acid erosion and recurrent F-T cycling, on one hand, soluble components of samples dissolve in acid solution, on the other hand, some surface layer of the sample peeled off caused by recurrent F-T cycling. Both of these damages are related to dry mass loss, therefore, dry mass loss is another aspect that reflects damage accumulation. Table 3 records average dry mass of sandstone before and after these experiments, and Figure 4 reflects changes of average dry mass loss of samples under coupled effect of acid corrosion and recurrent F-T cycling.

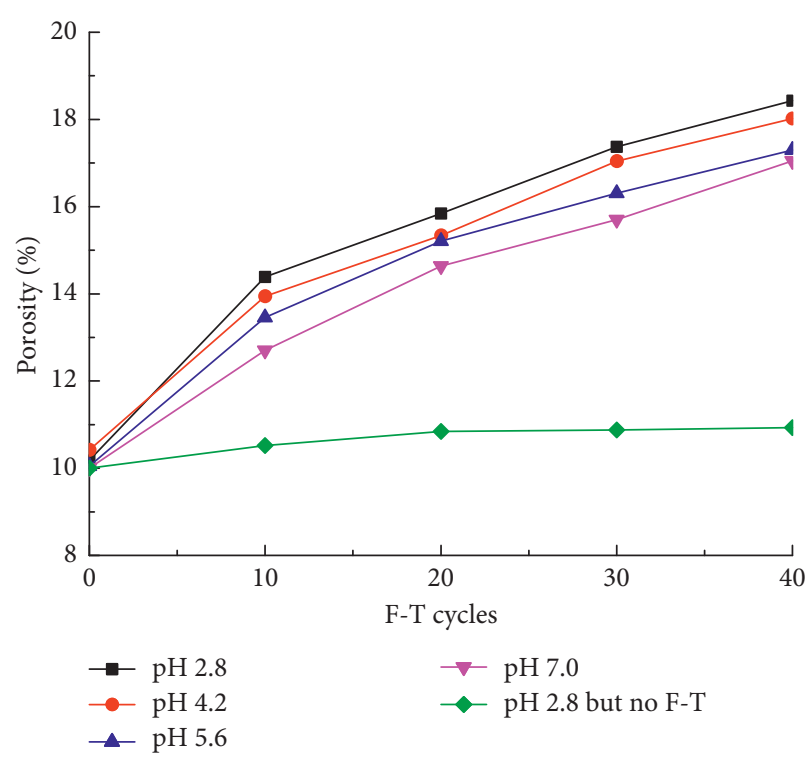

Figure 5: Porosity of sandstone after recurrent F-T cycles in acid solution with different $\mathrm{pH}$.

Table 3 and Figure 4 show that dry mass loss increases with acid corrosion and recurrent F-T cycling.

It is easy to find out that dry mass loss grows exponentially with increasing numbers of F-T cycles when samples are immersed in certain $\mathrm{pH}$ solution. Take those samples immersed in acid solution with a $\mathrm{pH}$ of 2.8 as example, dry mass loss corresponding to those samples that underwent 10, 20, 30, and $40 \mathrm{~F}-\mathrm{T}$ cycles is $0.915 \%, 1.765 \%$, $2.980 \%$, and $9.740 \%$ respectively. This group of data reveals that dry mass loss of samples is not serious before $20 \mathrm{~F}-\mathrm{T}$ cycles, while they suffer dramatic dry mass loss when F-T cycles reached 30 and 40 , which shows a exponential growth trend. Dry mass loss grows nearly linear with $\mathrm{pH}$ decrease when samples go through certain F-T cycles. Take those samples that underwent $30 \mathrm{~F}-\mathrm{T}$ cycles for example, dry mass loss corresponding to those samples immersed in acid solution with $\mathrm{pH}$ of $2.8,4.2,5.6$, and 7.0 is $2.980 \%, 2.770 \%$, $2.265 \%$ and $4.925 \%$ respectively.

Figure 4 shows that samples' dry mass loss increase with solution's $\mathrm{pH}$ decrease and F-T cycle increase, while the increasing trend of samples' mass is different. Dry mass loss grows exponentially with increasing numbers of F-T cycles while it grows nearly linear with $\mathrm{pH}$ decrease. The difference indicates that even though both acid corrosion and recurrent F-T cycling cause damage to sandstone; however, the damage of recurrent F-T cycling to sandstone is greater overall.

3.3. Porosity. In this paper, porosity is obtained by the NMR system. NMR calculated porosity with parameters of the sample's moisture content (saturated situation) and the sample's volume, so the porosity can reflect cracks and pores inside the sample; therefore, porosity is an important parameter that reflects rock damage. Figure 5 shows sandstone's porosity after it suffered different numbers of 
recurrent F-T cycles in acid solution with different $\mathrm{pH}$. A group of samples which immersed in acid solution with $\mathrm{pH}$ of 2.8 but did not suffer any F-T cycling is picked as the control group. In terms of the control group, during the first time-span of $10 \mathrm{~F}-\mathrm{T}$ cycles, the porosity increased from $10.00 \%$ to $10.52 \%$, whose growth accounts for more than $60 \%$ of the total pore growth $(0.82 \%)$ of the sample. In the second time-span of $10 \mathrm{~F}-\mathrm{T}$ cycles, the samples' porosity reached their peak and remained the same in the next 2 timespan of 10 F-T cycles, which indicates that acid corrosion took effect in first time-span of $20 \mathrm{~F}-\mathrm{T}$ cycles.

In terms of those samples which suffered couple effect of acid corrosion and F-T cycling, a quicker porosity growth is observed in the first time-span of $20 \mathrm{~F}-\mathrm{T}$ cycles and then porosity growth slows down, this also means that acid corrosion worked in the first time-span of $20 \mathrm{~F}-\mathrm{T}$ cycles. However, an obvious difference is that F-T cycling caused greater damage to samples. Take the group of samples immersed in acid solution with $\mathrm{pH}$ of 2.8 (Figure 5) as an example, during the first time-span of $10 \mathrm{~F}-\mathrm{T}$ cycles, the porosity increased from $10.18 \%$ to $14.39 \%$, and their porosity reached to $18.43 \%$ after 40 times of $\mathrm{F}$ - T cycles. It means that coupled effect of F-T cycling and acid erosion causes greater damage than acid erosion. Comparing the porosity of samples immersed in solution with different $\mathrm{pH}$, it reveals that the growth of porosity is positively related to the concentration of the acid solution, which reflected in Figure 5 is that the lower the solution's $\mathrm{pH}$ is, the bigger the porosity growth is.

3.4. T2 Spectrum. T2, that is, transverse relaxation time, is a parameter that represents pore's size inside rock samples. Big T2 value represents macropore and small T2 value represents micropore. Figure 5 presents the T2 distributions of samples which suffered coupled effect of acid erosion and recurrent F-T cycles. It is found that there are two peaks in the spectrum of these specimens. From left to right, the first spectral peak corresponds to micropores, while the right peaks represent macropores. The change rule of $\mathrm{T} 2$ spectrum of sandstone that underwent coupled effect of acid corrosion and recurrent $\mathrm{F}-\mathrm{T}$ cycles can be revealed in two perspectives.

Firstly, from the perspective of F-T cycles, porosity increases with the increase in F-T cycles overall. During the first time-span of $10 \mathrm{~F}-\mathrm{T}$ cycles, the T2 spectrum shifts to the right as a whole, indicating that new pores continuously generated and primary pores expanded to a larger size under the coupled effect of F-T cycling and acid erosion. In the second time-span of $10 \mathrm{~F}$-T cycles, left peaks of four pictures in Figure 6 gain a considerable growth while the right peaks basically remain the same, which means micropores increased rapidly while macropores had no evident change during this period. During the third and fourth time-span of $10 \mathrm{~F}-\mathrm{T}$ cycles, the right peak of the T2 spectrum increases rapidly while the left peak basically remains the same, indicating that the macropores in the sample developed rapidly while micropores had no evident change at this stage.

Secondly, from the perspective of $\mathrm{pH}$ variation, the difference of the $\mathrm{T} 2$ spectrum between samples immersed in acid solution with different $\mathrm{pH}$ mainly reflects in the first timespan of $10 \mathrm{~F}-\mathrm{T}$ cycles. Figure 6 shows a trend of the T2 spectrum in the first time-span of $10 \mathrm{~F}-\mathrm{T}$ cycles that the rightshift value of the left peak increases with the decrease of $\mathrm{pH}$ value. This demonstrates that the rate of micropore growth increases with the decrease of the solution's $\mathrm{pH}$ value.

3.5. Solution's $p H$ and Metallic Ion Concentration. Acid solution will react with resolved components of sandstone when sandstone samples were immersed in acid solution. Figure 7 presents $\mathrm{pH}$ change of solutions immersed with sandstone samples which underwent treatment of various $\mathrm{pH}$ values and F-T cycles. It can be seen from Figure 7 that these $\mathrm{pH}$ values change dramatically within $20 \mathrm{~F}-\mathrm{T}$ cycles, and after that $\mathrm{pH}$ values are almost unchanged. The phenomenon demonstrates that acid corrosion mainly happened at the beginning $20 \mathrm{~F}-\mathrm{T}$ cycles, and this result is consistent with the conclusion we got from Section 2.5. While the line in Figure 7 marked with $\mathrm{pH} 7.0$ which represents sandstone immersed with pure water shows a downward trend, that means, , pure water, not like other solutions, turns to acid solution when sandstone was soaked in it. As sandstone used in this paper was composed of quartz, illite, montmorillonite, and clay, the acidification of pure water was caused by the hydroxyl groups on the crystal surface of illite and montmorillonite reacted with the $\mathrm{OH}^{-}$ produced by hydrolysis under neutral conditions. Its chemical reaction is shown as follows:

$$
\mathrm{Al}-\mathrm{OH}+\mathrm{OH}^{-}+\mathrm{H}^{+} \longrightarrow \mathrm{Al}-\mathrm{O}^{-}+\mathrm{H}_{2} \mathrm{O}+\mathrm{H}^{+}
$$

Figure 8 presents metallic ion concentrations of the solution with $\mathrm{pH}$ of 2.8 after different F-T cycles. The solution contained 4 metal ions altogether, that is, $\mathrm{K}^{+}, \mathrm{Mg}^{2+}$, $\mathrm{Fe}^{3+}$, and $\mathrm{Al}^{3+}$. As shown in Figure 8, the metallic ion concentrations increase mainly within the first time-span of 20 F-T cycles, and compared with Figure 7, it can be found that acid was consumed. Combining the chemical component of sandstone and the metallic component of the solution demonstrate the chemical reactions between sandstone and sulfuric acid solutions as described below:

$$
\begin{gathered}
\mathrm{K}_{x}\left(\mathrm{H}_{2} \mathrm{O}\right)_{4}\left(\mathrm{Al}_{2-x} \mathrm{Mg}_{x}\right)\left[\mathrm{Si}_{4} \mathrm{O}_{10}\right](\mathrm{OH})_{2}+\mathrm{H}_{2} \mathrm{O}+\mathrm{H}^{+} \longrightarrow \\
\mathrm{K}^{+}+\mathrm{Mg}^{2+}+\mathrm{Al}_{2} \mathrm{O}_{3} \cdot 2 \mathrm{SiO}_{2} \cdot 2 \mathrm{H}_{2} \mathrm{O}+\mathrm{H}_{4} \mathrm{SiO}_{4}
\end{gathered}
$$

$$
\begin{gathered}
\mathrm{K}_{1-x}\left(\mathrm{H}_{2} \mathrm{O}\right)_{x}\left\{\mathrm{Al}_{2}\left[\mathrm{AlSi}_{3} \mathrm{O}_{10}\right](\mathrm{OH})_{2-x}\left(\mathrm{H}_{2} \mathrm{O}\right)_{x}\right\}+\mathrm{H}_{2} \mathrm{O}+\mathrm{H}^{+} \longrightarrow \\
\mathrm{K}^{+}+\mathrm{Al}^{3+}+\mathrm{Al}_{2} \mathrm{O}_{3} \cdot 2 \mathrm{SiO}_{2} \cdot 2 \mathrm{H}_{2} \mathrm{O}+\mathrm{H}_{4} \mathrm{SiO}_{4}
\end{gathered}
$$

$$
\mathrm{Al}_{2} \mathrm{O}_{3} \cdot 2 \mathrm{SiO}_{2} \cdot 2 \mathrm{H}_{2} \mathrm{O}+6 \mathrm{H}^{+}=2 \mathrm{Al}^{3+}+2 \mathrm{H}_{2} \mathrm{SiO}_{3}+3 \mathrm{H}_{2} \mathrm{O}
$$

$$
\mathrm{Fe}_{2} \mathrm{O}_{3}+6 \mathrm{H}^{+}=6 \mathrm{Fe}^{3+}+3 \mathrm{H}_{2} \mathrm{O}
$$

When immersed in sulfuric acid solution, montmorillonite reacted with it, and the reaction equation is shown as 


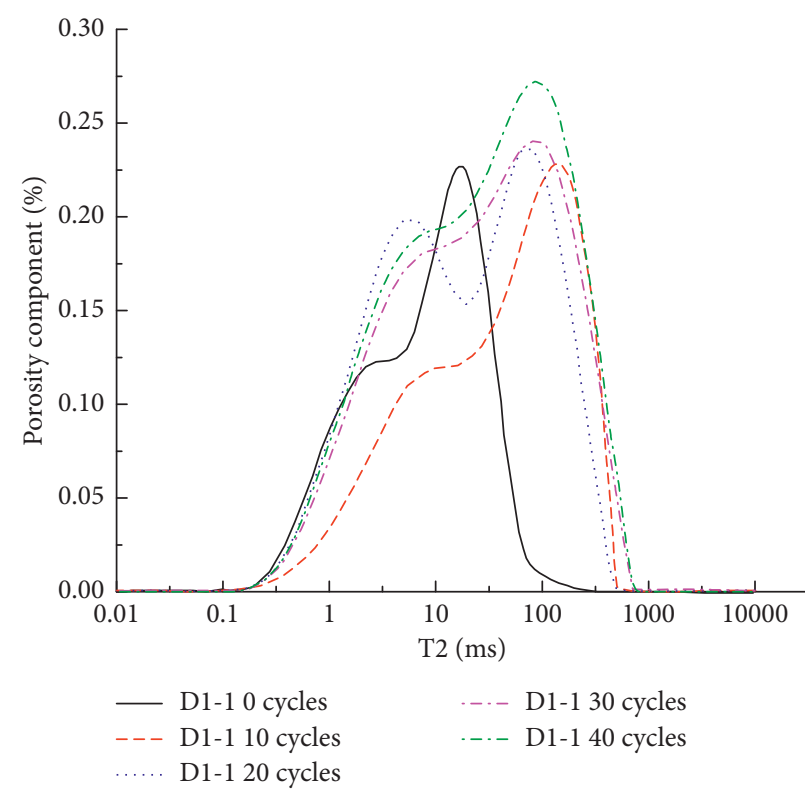

(a)

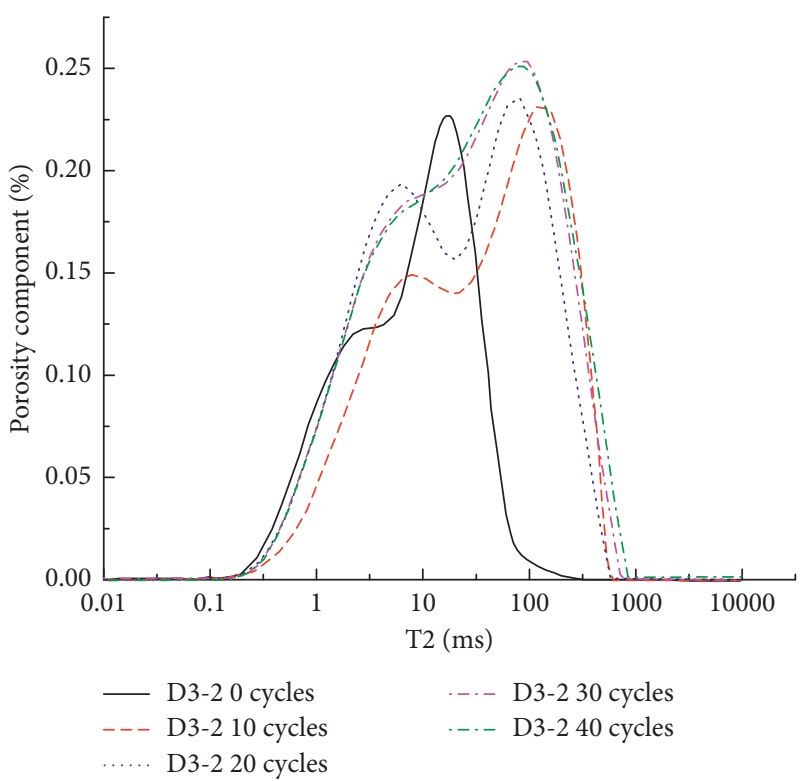

(c)

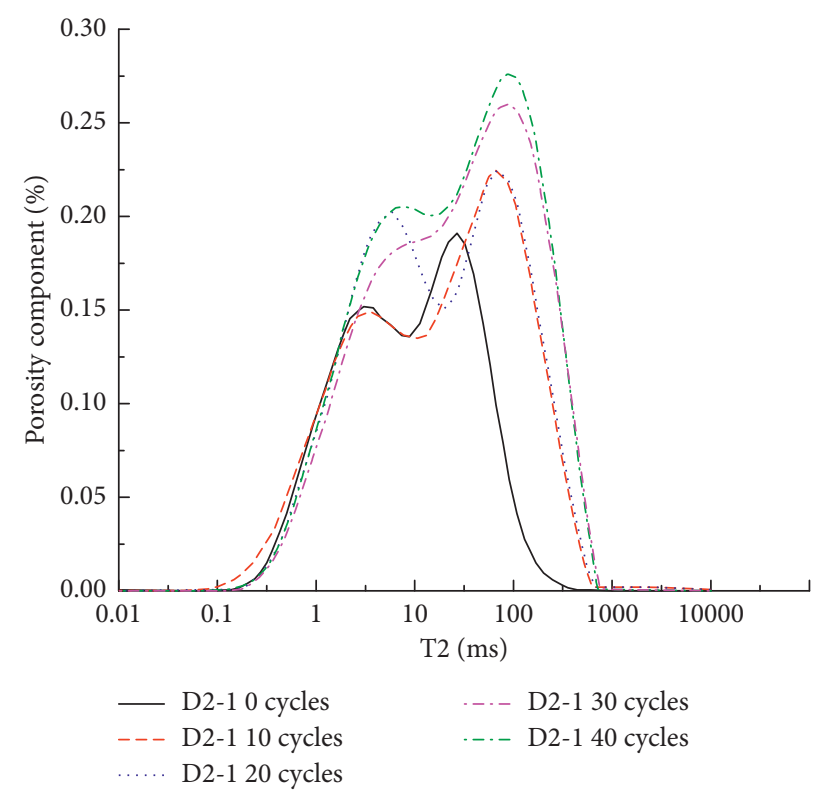

(b)

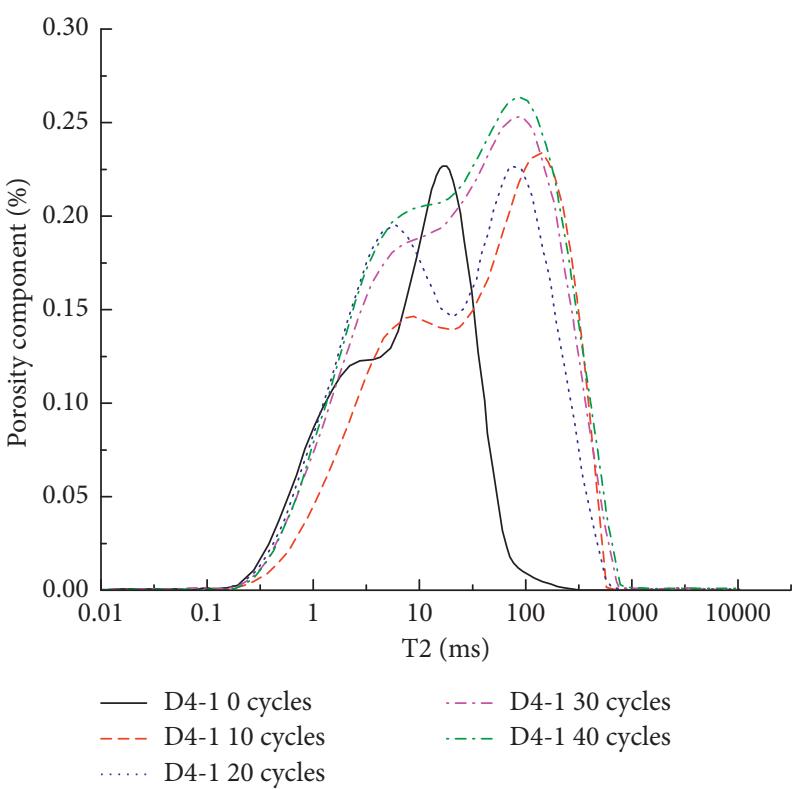

(d)

Figure 6: T2 spectrum of sandstone that underwent coupled effect of acid corrosion and recurrent F-T cycles. (a-d) Samples immersed in solution with $\mathrm{pH}$ of $2.8,4.2,5.6$, and 7.0.

(2). Equation (2) shows that $\mathrm{K}^{+}$and $\mathrm{Mg}^{2+}$ are replaced by $\mathrm{H}^{+}$ from montmorillonite, kaolinite, and orthosilicic acid generated at the same time. Equation (3) shows that $\mathrm{K}^{+}, \mathrm{Al}^{3+}$, kaolinite, and orthosilicic acid generated when sulfuric acid solution reacted with illite. It is worth noting that kaolinite do react with sulfuric acid solution only after $\mathrm{K}^{+}$and $\mathrm{Mg}^{2+}$ are separated from illite and montmorillonite, so (4) gives another resource of $\mathrm{Al}^{3+}$ and $\mathrm{Fe}^{3+}$ in solution came from clay in sandstone; when ferric oxide in clay reacts with sulfuric acid solution, $\mathrm{Fe}^{3+}$ would generate as shown in (5).

In conclusion, when sandstone is immersed in sulfuric acid solution, soluble components like montmorillonite, illite, and ferric oxide in clay react with sulfuric acid solution.
As major cements and fillings of sandstone, when these components dissolve, micropores generate and primary pores expand. This explains why the solution's $\mathrm{pH}$, metallic ion concentrations, and numbers of micropore rise, and dry mass of samples decline in the first time-span of $20 \mathrm{~F}-\mathrm{T}$ cycles.

3.6. Magnetic Resonance Images (MRI). As energy attenuation characteristic varies with the compositions of rock, the distribution of different compositions can be detected based on the difference of attenuation signals. In MRI, the locations of fluid within rocks are shown as light spots, and the 


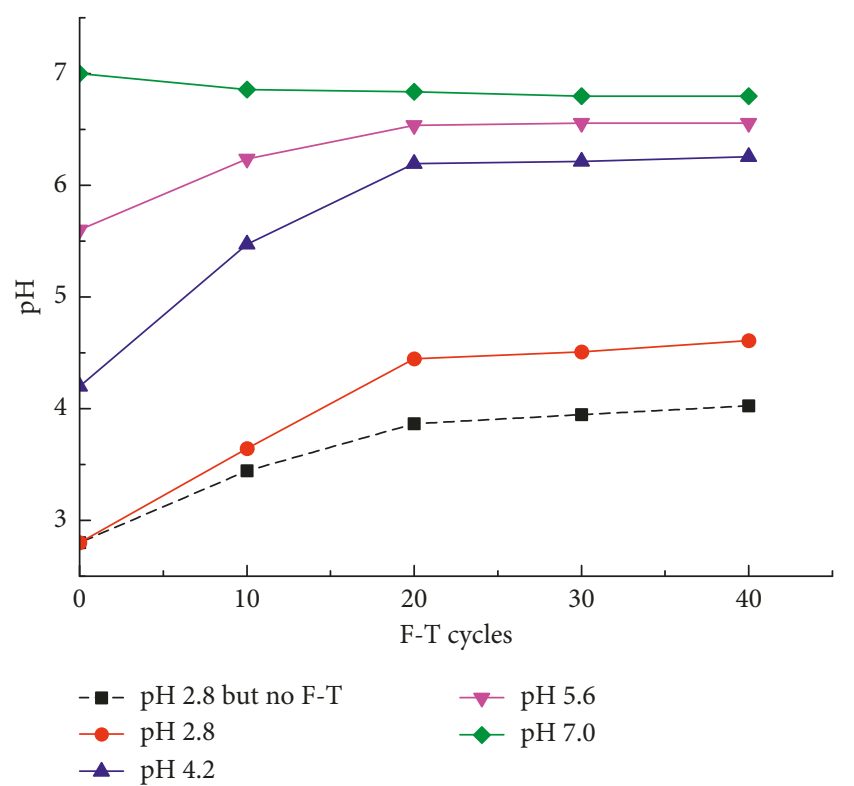

FIgURE 7: pH change of solutions immersed with sandstone after different F-T cycles.

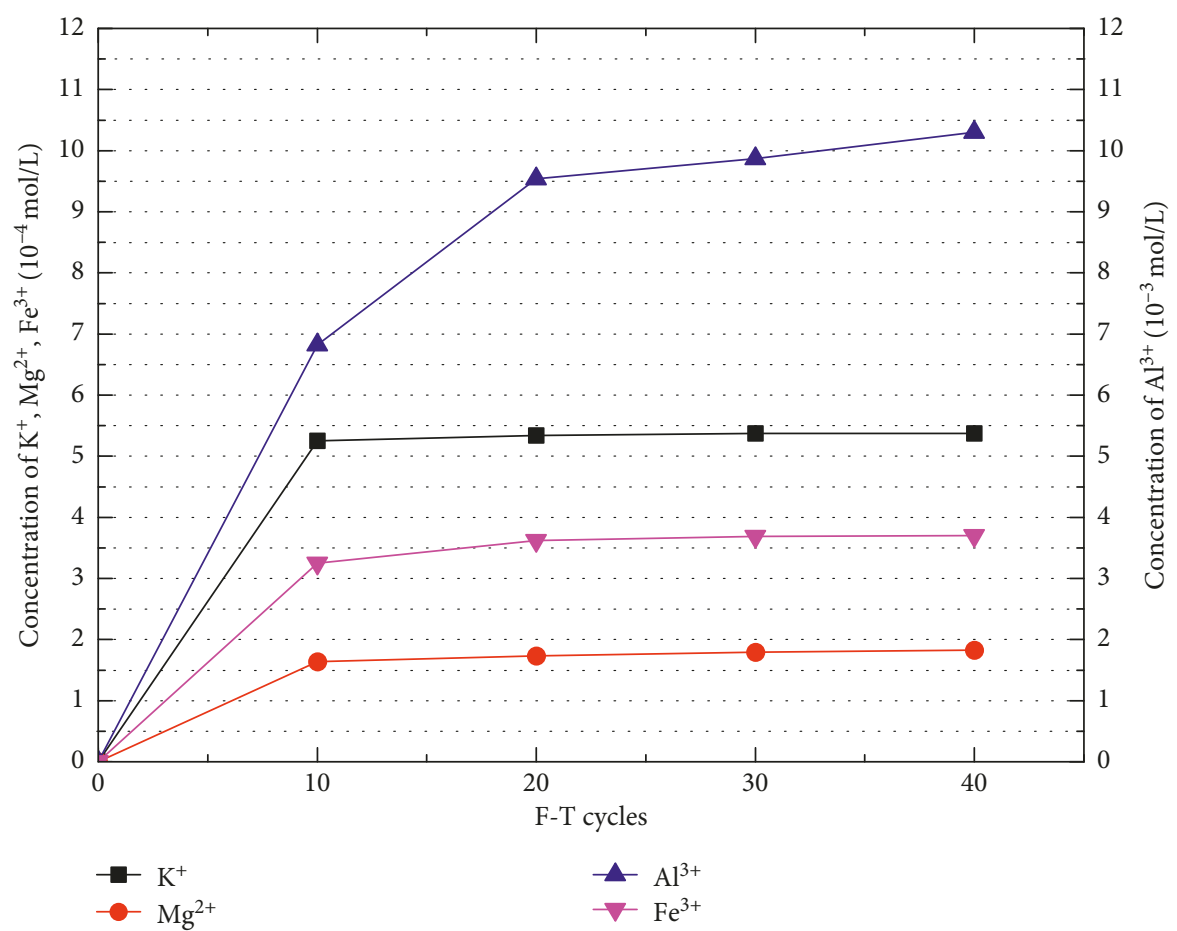

Figure 8: Metallic ion concentrations of solution $(\mathrm{pH}=2.8)$ immersed with sandstone after different F-T cycles.

fluid content of samples is reflected by the brightness of light spots. The brighter and larger the light spots are, the higher the fluid content is, which means that the pores are more abundant and larger [29].

In this study, the MRI imaging was conducted on the saturated specimens to intuitively show the change of pore sizes and pore structures after the treatment of acid erosion and recurrent F-T cycling. Figure 9 gives MRI test result of sandstone samples immersed in acid solution with $\mathrm{pH}$ of 2.8 which underwent different F-T cycles.

As shown in Figure 9, the number and the brightness of light spot of sandstone samples increase with the increase 


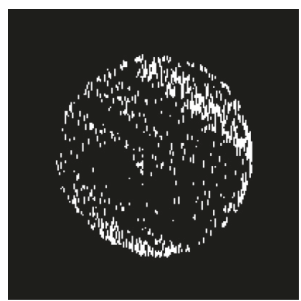

(a)

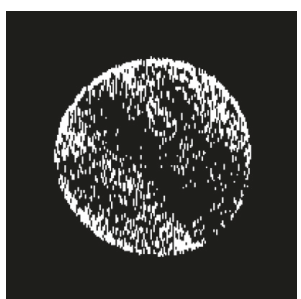

(b)

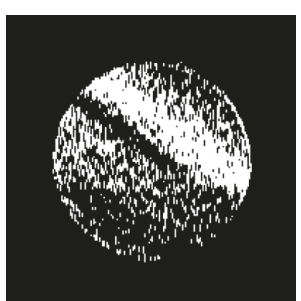

(c)

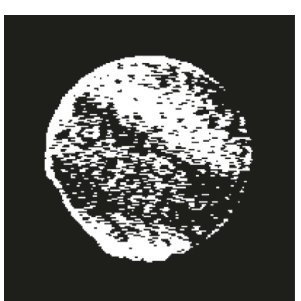

(d)

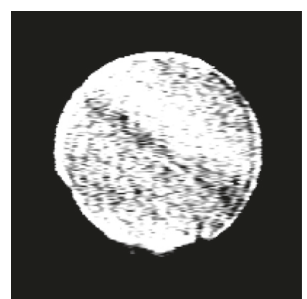

(e)

FIGURE 9: MRI of sandstone which underwent coupled effect of acid erosion ( $\mathrm{pH}=2.8)$ and recurrent F-T cycling. (a) 0 F-T cycles, (b) 10 F-T cycles, (c) 20 F-T cycles, (d) 30 F-T cycles, and (e) 40 F-T cycles.

of F-T cycles, which means that pore numbers and pore size of sandstone samples increase with the increase of F-T cycles. As to the saturated sample which suffered 0 F-T cycles, light spots are mainly distributed around the surface, and some light spots are scattered inside the sample. After $10 \mathrm{~F}-\mathrm{T}$ cycles, it could be found that light spot extends to the inner of the sample, and some light spots become brighter, which reveals that new micropores are formed and some micropores expand to a larger size inside the rock. After $20 \mathrm{~F}-\mathrm{T}$ cycles, light spots generate continuously and are more intensive; this indicates that more micropores generated during this period. After $30 \mathrm{~F}-\mathrm{T}$ cycles, it is obvious that more brighter light spots occur, and it is worth noting that the image is not circular anymore, which means that some part of the surface peeled off from the samples. After $40 \mathrm{~F}-\mathrm{T}$ cycles, more pores generate, and the peeling off area on the sample surface gets bigger.

\section{Conclusions}

(1) According to the samples' appearance and MRI, it can be concluded that sandstone samples which underwent coupled effect of acid erosion and recurrent F-T cycles are destroyed from outside to inside. Visible holes and small cracks are formed firstly on the surface of samples and then developed inside samples.

(2) Dry mass loss and porosity grow with F-T cycle increase and $\mathrm{pH}$ value decrease. It reveals that deterioration of sandstone enhanced with the decrease of the solution's $\mathrm{pH}$ and increase of F-T cycles. In addition, it can also be seen that coupled effect of acid corrosion and recurrent F-T cycling causes much more serious deterioration to sandstone samples than acid corrosion.

(3) The NMR T2 distribution of sandstones is represented by a two-peak spectrum. The variation of T2 spectrum shows that acid erosion and F-T cycling lead to the generation of new micropores and expansion of micropores at the beginning; when acid solution is exhausted, new micropores generate under the effect of F-T cycling, and micropores in samples keep developing and expanding with the increase of F-T cycles.
(4) The solution's $\mathrm{pH}$ and concentration of $\mathrm{K}^{+}, \mathrm{Mg}^{2+}$, $\mathrm{Fe}^{3+}$, and $\mathrm{Al}^{3+}$ increase with the increase of F-T cycle. According to the mineral component of the sample and composition of the solution after reaction, it can be concluded that montmorillonite, illite, and clay in sandstone react with sulfuric acid solution, which consumed $\mathrm{H}^{+}$of the solution and separated out corresponding metallic ions.

\section{Data Availability}

The data used to support the findings of this study are available from the corresponding author upon request.

\section{Conflicts of Interest}

The authors declare that they have no conflicts of interest.

\section{Acknowledgments}

The support from National Natural Science Foundation of China (Grant nos. 51774323 and 41502327) and the Fundamental Research Funds for the Central Universities of Central South University (2018zzts213) is sincerely appreciated.

\section{References}

[1] J. Park, C. U. Hyun, and H. D. Park, "Changes in microstructure and physical properties of rocks caused by artificial freeze-thaw action," Bulletin of Engineering Geology and the Environment, vol. 74, no. 2, pp. 555-565, 2014.

[2] P. Wang, J. Y. Xu, S. Liu, H. Wang, and S. Liu, "Static and dynamic mechanical properties of sedimentary rock after freeze-thaw or thermal shock weathering," Engineering Geology, vol. 210, pp. 148-157, 2016.

[3] Q. S. Liu, S. B. Huang, Y. S. Kang, and X. Liu, “A prediction model for uniaxial compressive strength of deteriorated rocks due to freeze-thaw," Cold Regions Science and Technology, vol. 120, pp. 96-107, 2015.

[4] F. Mustafa and I. Ismail, "Effects of the freeze-thaw (F-T) cycle on the andesitic rocks (Sille-Konya/Turkey) used in construction building," Journal of African Earth Sciences, vol. 109, pp. 96-106, 2015.

[5] G. Mainali, S. Dineva, and E. Nordlund, "Experimental study on debonding of shotcrete with acoustic emission during freezing and thawing cycle," Cold Regions Science and Technology, vol. 111, pp. 1-12, 2015. 
[6] N. Matsuoka and H. Sakai, "Rock fall activity from an alpine cliff during thawing periods," Geomorphology, vol. 28, no. 3-4, pp. 309-328, 1999.

[7] D. H. Everett, "The thermodynamics of frost damage to porous solids," Transactions of the Faraday Society, vol. 57, pp. 1541-1551, 1961.

[8] M. Steiger, "Crystal growth in porous materials I: the crystallization pressure of large crystals," Journal of Crystal Growth, vol. 282, no. 3-4, pp. 455-469, 2005.

[9] M. Steiger, "Crystal growth in porous materials II: influence of crystal size on the crystallization pressure," Journal of Crystal Growth, vol. 282, no. 3-4, pp. 470-481, 2005.

[10] D. K. Tim, A. B. Marijn, D. S. Thomas et al., "A pore-scale study of fracture dynamics in rock using X-ray micro CT under ambient freeze-thaw cycling," Environmental Science \& Technology, vol. 49, no. 5, pp. 2867-2874, 2015.

[11] C. Walbert, J. Eslami, A. L. Beaucour, A. Bourges, and A. Noumowe, "Evolution of the mechanical behavior of limestone subjected to freeze-thaw cycles," Environmental Earth Sciences, vol. 74, no. 7, pp. 6339-6351, 2015.

[12] T. C. Powers and R. A. Helmuth, "Theory of volume changes in hardened Portland cement paste during freezing," in Proceedings of the Highway Research Board, vol. 32, pp. 285-297, Washington, DC, USA, January 1953.

[13] I. Vlahou and M. G. Worster, "Ice growth in a spherical cavity of a porous medium," Journal of Glaciology, vol. 56, no. 196, pp. 271-277, 2010.

[14] S. Wiman, "A preliminary study of experimental frost weathering," Geografiska Annaler, vol. 45, no. 2-3, pp. 113$121,1963$.

[15] M. Hori and H. Morihiro, "Micromechanical analysis on deterioration due to freezing and thawing in porous brittle materials," International Journal of Engineering Science, vol. 36, no. 4, pp. 511-522, 1998.

[16] H. Yavuz, "Effect of freeze-thaw and thermal shock weathering on the physical and mechanical properties of an andesite stone," Bulletin of Engineering Geology and the Environment, vol. 70, no. 2, pp. 187-192, 2010.

[17] F. Bayram, "Predicting mechanical strength loss of natural stones after freeze-thaw in cold regions," Cold Regions Science and Technology, vol. 83-84, pp. 98-102, 2012.

[18] A. Al-Omari, K. Beck, X. Brunetaud, A. Török, and M. AlMukhtar, "Critical degree of saturation: a control factor of freeze-thaw damage of porous lime stones at Castle of Chambord, France," Engineering Geology, vol. 185, no. 3, pp. 71-80, 2015.

[19] M. Akin and A. Özsan, "Evaluation of the long-term durability of yellow travertine using accelerated weathering tests," Bulletin of Engineering Geology and the Environment, vol. 70, no. 1, pp. 101-114, 2011.

[20] M. Mutluturk, R. Altidag, and G. Turk, “A decay function model for the integrity loss of rock when subjected to recurrent cycles of freezing-thawing and heating-cooling," International Journal of Rock Mechanics and Mining Sciences, vol. 41, no. 2, pp. 237-244, 2004.

[21] M. H. Ghobadi and R. Babazadeh, "Experimental studies on the effects of cyclic freezing-thawing, salt crystallization, and thermal shock on the physical and mechanical characteristics of selected sandstones," Rock Mechanics and Rock Engineering, vol. 48, no. 3, pp. 1001-1016, 2015.

[22] K. P. Zhou, B. Li, J. L. Li, H. W. Deng, and F. Bin, "Microscopic damage and dynamic mechanical properties of rock under freeze-thaw environment," Transactions of Nonferrous Metals Society of China, vol. 25, no. 4, pp. 1254-1261, 2015.
[23] L. J. Feucht and J. M. Logan, "Effects of chemically active solutions on shearing behavior of a sandstone," Tectonophysics, vol. 175, no. 1-3, pp. 159-176, 1990.

[24] X. T. Feng, S. L. Chen, and H. Zhou, "Real-time computerized tomography (CT) experiments on sandstone damage evolution during triaxial compression with chemical corrosion," International Journal of Rock Mechanics and Mining Sciences, vol. 41, no. 2, pp. 181-192, 2004.

[25] H. W. Deng, C. F. Dong, J. L. Li, K. P. Zhou, W. G. Tian, and J. Zhang, "Experimental study on sandstone freezing-thawing damage properties under condition of water chemistry," Applied Mechanics and Materials, vol. 608-609, pp. 726-731, 2014.

[26] T. Han, J. Shi, Y. Chen, and Z. Li, "Effect of chemical corrosion on the mechanical characteristics of parent rocks for nuclear waste storage," Science and Technology of Nuclear Installations, vol. 2016, Article ID 7853787, 11 pages, 2016.

[27] S. J. Miao, M. F. Cai, Q. F. Guo, P. Wang, and M. Liang, "Damage effects and mechanisms in granite treated with acidic chemical solutions," International Journal of Rock Mechanics and Mining Sciences, vol. 88, pp. 77-86, 2016.

[28] J. L. Li, K. P. Zhou, W. J. Liu, and H. W. Deng, "NMR research on deterioration characteristics of microscopic structure of sandstones in freeze-thaw cycles," Transactions of Nonferrous Metals Society of China, vol. 26, no. 11, pp. 2997-3003, 2016.

[29] C. Liu, H. W. Deng, Y. Wang, Y. Lin, and H. Zhao, “Timevarying characteristics of granite microstructures after cyclic dynamic disturbance using nuclear magnetic resonance," Crystals, vol. 7, no. 10, p. 306, 2017. 


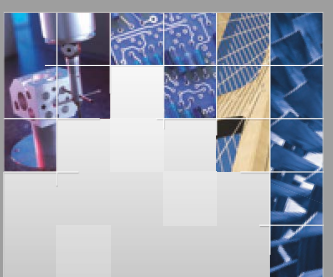

\section{Enfincering}
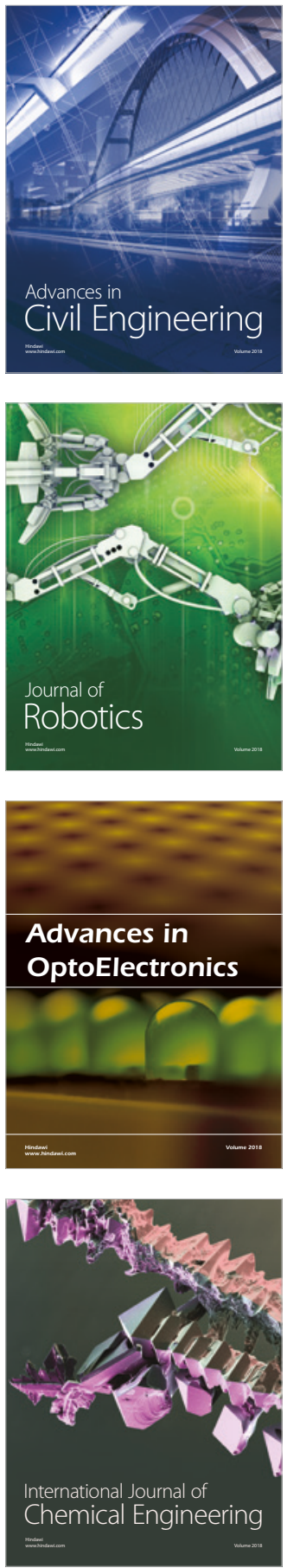

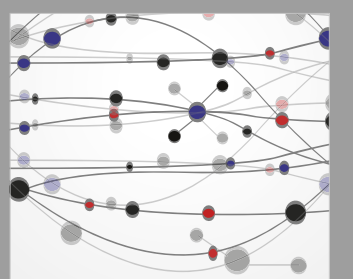

\section{Rotating \\ Machinery}

The Scientific World Journal

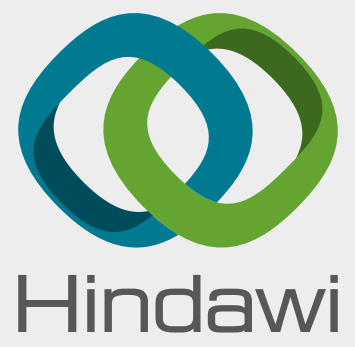

Submit your manuscripts at

www.hindawi.com
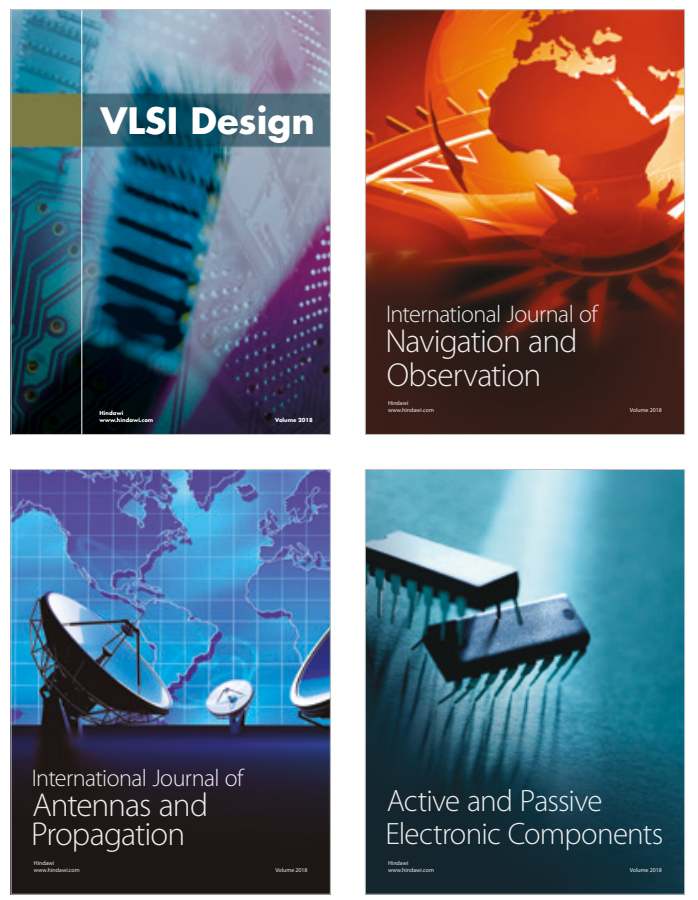
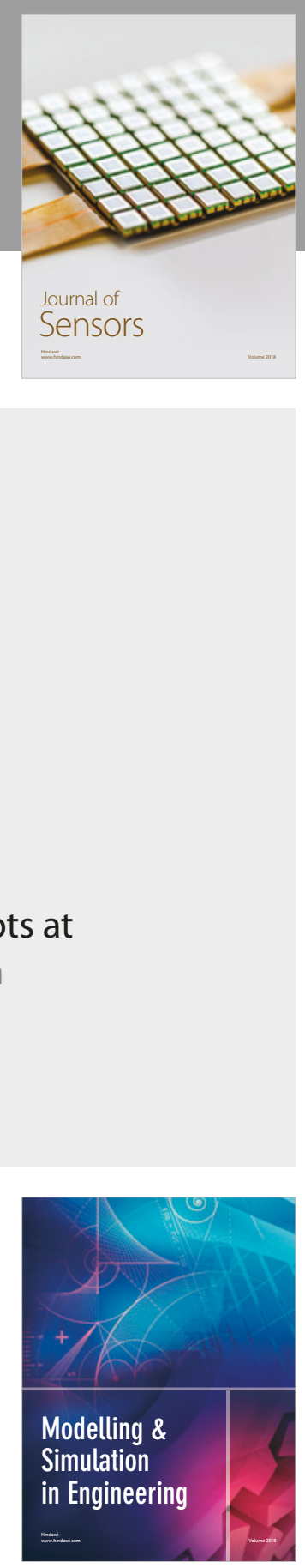

\section{Advances \\ Multimedia}
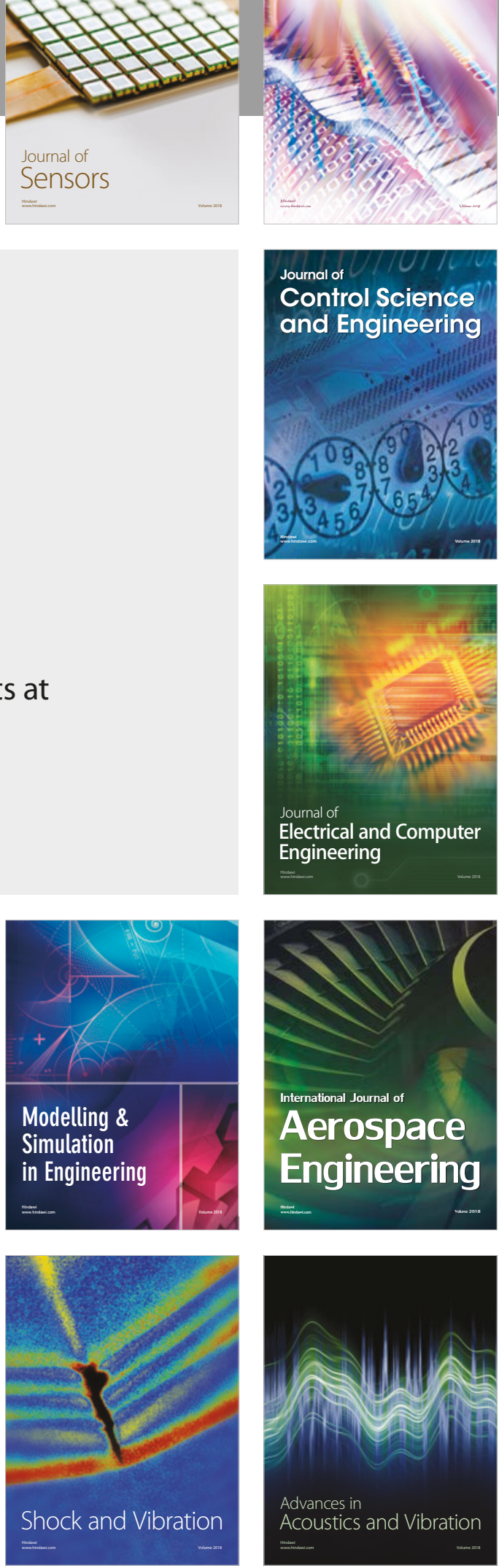